\title{
Assessing Intercultural Competence in Teacher Education: A Missing Link
}

\author{
Sapna Thapa
}

\begin{abstract}
This chapter discusses the importance of developing intercultural competence as a foundational strategy in teacher education. The primary argument asserts that specific, mandated-content assessments do not help newly trained teachers to develop skills and knowledge related to thoughtfulness, criticality, cultural responsiveness, and caring for the young individuals with whom they work. The author attributes this to the lack of intercultural sensitivity and intercultural communication in teacher education discourses. Researchers suggest that caring in schools and other such institutions have diminished as there are distinct gaps in the relationships between teachers and culturally diverse students causing these students to fall out of the school systems. The chapter informs about the need to equip teachers with intercultural sensitivities and intercultural communication skills to help them navigate the changing demographics in classrooms. Finally, it provides some insight into discovering missing links in teaching and pedagogical approaches and offers some strategies for bridging the ever-widening intercultural gaps.
\end{abstract}

Keywords Intercultural competence $\cdot$ Diversity $\cdot$ Teacher education

\section{Introduction}

Teaching in a mid-western University in Wisconsin (University of WisconsinStout), as a foreign instructor (non-American, Asian-Nepali), I discovered that my group of pre-service teachers view the rest of the world through, what many researchers call, a "monolingual-mono-cultural" lens (Fonseca-Greber 2010, 102; Kayes 2006; Dean 1989). Most of my pre-service teachers belong to a homogenous group of 'white Americans' who claim that teaching young children is what they want to do in the future. Almost all believe that their classrooms will consist of mostly 'white' children from middle-class families, who will speak English and

\footnotetext{
S. Thapa $(\bowtie)$

Early Childhood Teacher Education, University of Wisconsin-Stout, Menomonie, WI, USA

e-mail: thapas@uwstout.edu
}

H. Westerlund et al. (eds.), Visions for Intercultural Music Teacher Education, Landscapes: the Arts, Aesthetics, and Education 26, 
will have experiences similar to their own and their ancestors. Some acknowledge that their classrooms might have a few children from 'other' cultures and to accommodate these children, they would learn a few words and songs from the 'other' culture, display pictures of diverse people and talk about 'their' food. This narrow and deficit outlook towards children/people from different cultural backgrounds was very alarming to me. It was not surprising to note that many of them were unaware of the changing demographics in classrooms across the United States and those who were aware assumed that they would not be affected (Maxwell 2014; Florian 2017). I was worried about this outlook and their attitude towards diversity and the lack of knowledge regarding intercultural communication as it would limit their practice and become a barrier in their future profession, especially if they aimed to become inter-culturally competent, global leaders in education. Class discussions about culture, inclusiveness, and, intercultural competence/communication (ICC) also disclosed some disturbing comments. Similar to Weaver (1999) and Rottenburg's (2008) studies, many of my students indicated that culture was outside their 'American-ness' and that they were 'just white, middle-class Americans' who valued 'hard work and success'. So, in an attempt to develop strategies to help my pre-service teachers and students expand their knowledge about world cultures and acquire some semblance of intercultural competence, I participated in a research project called "Infusing diversity across the curriculum." In this chapter, I will give an overview of the project and explain why ICC discourses in teacher education are essential pedagogical approaches. I will argue the importance of understanding one's own culture and cultural background, beliefs and values as essential tools in understanding other world cultures, diversity and inclusion, and address the importance of applying a "caring pedagogy" and its inter-connectedness with ICC when working with very young children (Soto 2005). In conclusion, I will highlight the implications of ICC and its importance in teacher education and provide some strategies that could help pre-service teachers develop intercultural competence and connectedness in a highly evolving, globalized world (Soto 2005).

\section{Impacts of Mandated Assessments on Teacher Education and the Development of ICC}

As mentioned earlier, I have been teaching Early Childhood Teacher Education at UW-Stout for the past 5 years. The research assumptions below disclose how my pre-service teacher's attitudes and dispositions are related to the artifacts derived from socio-cultural interactions, cultural background and upbringing. I argue that encouraging pre-service teachers to critically reflect on their attitudes and dispositions will help them to develop a level of intercultural sensitivity and enhance their intercultural competence. Critical reflections will also help them to become empathetic and caring individuals rather than simply the savior of "poor minority children" as discovered by some scholars (Garmon 2005, 207; see also Madrid, Baldwin 
and Belbase 2016). Campbell, Thompson and Barrett suggest that "critical examination and analysis" of the self are the "means through which personal beliefs and images of teaching are explored" (2012, 80). Campbell et al. (2012), citing Britzman (1991), further add that teachers are influenced by the practices in social environments and by the values, beliefs and histories of self. Therefore, if we are to prepare successful and effective teachers who will care for all children and strive to "improve [the] human condition, and meet the challenges of a changing world" we have to begin by "sensitizing" them "to the values of others and seeing/experiencing the world through the language and culture of another" (Fonseca-Greber 2010, 102).

However, these suggestions could be pipedreams as recent shifts towards systemic and standardized assessments for pre-service teachers has changed the landscape of teacher education in the United States. Several teacher preparation programs across the country are scrambling to succeed in the competitive licensure examination called the "edTPA" (Educator/tion Teacher Performance Assessment). Many university courses are being revised to fulfill the assessment's objectives. According to Legwell and Oyler, the edTPA is a "high-stakes summative assessment for teaching candidates while generating formative feedback for candidates and programs" $(2016,131)$. Recent literature has accused the edTPA assessment system of excluding contextualized cultural issues and ignoring the development of important skill sets such as cultural and intercultural competence despite the relevance of inclusivity and diversity in many school systems today (Cochran-Smith et al. 2016). Many scholars agree that standardization is an outcome of the intense emphasis on globalization. Globalization authorizes success through competitive means and the enhancement of productivity through skilled citizens, which then translates into economic efficiency of nations. Sahlberg suggests that globalization benefits education by integrating "world cultures" but also segregates and marginalizes individuals and communities $(2004,66)$.

Barton suggests "marriages between capitalism and education" accentuates commercialism "at the expense of social justice and human dignity" (2001, 847). Due to this massive corporate movement, newly trained teachers are going out into the field with little or no skills or knowledge related to thoughtfulness, criticality, cultural responsiveness, and caring for young individuals with whom they work (Trainer 2012). These mandates and standardization are very relevant in UW-Stout's teacher education. As instructors, we are more focused on supporting our preservice teachers to pass the edTPA rather than developing intercultural sensitivity and competence in cultural diversity, inclusion etc. Although we include and teach topics, such as differentiation and adaptations to help pre-service teachers plan appropriate lessons for young children, we forget to include the important pedagogy of care in our lectures. In the absence of care, celebrations of differences and support for diverse children cannot be possible as minority children will always need differentiation and adaptations. Weiner states, targeting "specific students, those presumed to need extra help" is an assumption that "poor, minority children do not succeed in schools because they and their families are defective" $(2007,276)$. This is true in our teacher education, since we direct our pre-service teachers to focus on meeting specific and targeted needs of academically challenged children in technical 
and robotic ways rather than guiding them to look for reasons behind that need - in other words, we intentionally tell them to forego care and avoid relationships; we are teaching teachers to identify weaknesses of students rather than guiding them to work with the strengths of students.

With the mandated assessments, we are moving further and further away from developing meaningful relationships with students. We are negating the value of critical self-reflection, intentionality, flexibility and care. This could very well be one of the reasons that many of my students declared that all they had to do was learn a few words of another language, hang pictures and have some cultural items to accommodate diverse groups of children. According to high volumes of research, many parents want more for their children than just a score on a standardized test (Zeichner 2006). Zeichner adds that focusing on higher test scores eliminates teachers from supporting their students in achieving success in other important areas such as "social learning, aesthetic learning and civic learning" (2006, 333). We cannot only focus on preparing "good enough" teachers who are "low-level technicians" adjusting to the needs of specific minority children but must also support our prestudent teachers in understanding the complexity of the teaching profession and its intimate relation to care and empathy (Zeichner 2006, 333; see also Hartlep et al. 2015). Hence, I argue that, if our teachers are to become successful leaders, it is critical for them to care about the children and families with whom they work by becoming knowledgeable about their culture, their backgrounds and their values. We must encourage teachers to move away from the deficit model of working with the weaknesses of children from poor and marginalized groups. Pre-service teachers must be guided to investigate their biases through critical reflections and discussions about their own cultures, backgrounds and their life experiences. They must be encouraged to be sensitive towards others and their cultures and to be competent in navigating the changing demographics and contribute towards bridging the widening gaps between cultures, ethnicities and socio-economies.These would then enhance efficiency, professionalism, flexibility and intentionality.

\section{Culture: Definitions and Care Theory as a Basis for Intercultural Sensitivity}

Wursten and Jacobs (2013) suggest that the dominant cultural trait of the USA is 'masculinity,' and often Americans view culture objectively through "institutional aspects" such as art, music, cuisine and peoples (Bennett and Bennett 2004, 150). Fonseca-Greber perceives this simplistic view as a the "monolingual-mono-cultural national identity" and informs that "sensitizing Americans to the value of seeing the world through the language-culture of another" can be challenging $(2010,102)$. The word 'culture,' many scholars agree, is ambiguous. There is a myriad of definitions, which are co-constructed and contextualized based on values, polices, practices and on the nature of social interactions. Many scholars also agree that the dominant 
cultural, social, political and economic value of any particular context play a vital role in the development of intercultural competence and intercultural communication. For example, Dai and Ming-Chen (2014) state that ICC is influenced by the predominant culture and becomes obvious only through a rigorous process of socialization. Similarly, Rissanen, Kuusisto and Kuusisto suggest that ICC is a "contextual, never-ending and unpredictable process" whereby "intercultural sensitivity" forms the basis of accepting others despite their differences $(2016,447)$. Based on the development model provided by Bennett and Bennett, intercultural sensitivity is achieved when one is able to change oneself affectively, cognitively, and behaviorally and "move from ethnocentrism to ethno-relativism" $(2004,1)$. They designate six distinct stages of experiences during the transformation from ethnocentrism to ethno-relativism with "denial of cultural differences" being the most extreme experience. This stage is followed by "defense and minimization" of cultural differences. The final stage, Bennett and Bennett state, is to accept cultural differences so that one is able to adapt and integrate those differences into personal "identity" $(2004,1)$. Other definitions of ICC suggest that it is the ability to "adeptly navigate complex environments marked by a growing diversity of peoples, cultures and lifestyles" (United Nations Educational Scientific and Cultural Organization 2013, 5). A large volume of literature suggests that ICC is more apparent in professions related to care, such as medicine and nursing. However, recent discourses propose that the foundational principle of teaching is also based on caring. Care in education relates to intentionality, flexibility, developing meaningful relationships, and openness towards cultural and other differences; these are the attributes of intercultural sensitivity (Garmon 2004; Soto 2005; Zeichner 2006). Dai and Ming-Chen suggests that ICC requires one to develop a "global mind-set," which is "closely related to individuals' affective, cognitive, and behavioral abilities" $(2014,6)$. In other words, individuals with a global mind-set are culturally sensitive (affective), open, knowledgeable and flexible (cognitive) and think critically and holistically (behavioral) to benefit the larger community (Dai and Ming-Chen 2014). (On this matter see recommended reading at the end of this chapter.)

However, masculine cultures support individualistic values of "achievement and success," hence there is little emphasis and motivation to cultivate caring for others or to acquire cultural knowledge of people from another culture (Wursten and Jacobs 2013, 10). For example, Darling-Hammond informs that many American schools "offer fewer opportunities for teachers to come to know students well during long periods of time" $(2006,6)$, even when most "students perceive the school community as a caring institution" (Soto 2005, 859). Care theory, according to Soto, accentuates fostering positive relationships between teachers and students to validate "students' cultural values and beliefs" and to promote engagement and commitment between the two parties $(2005,864)$. Soto adds that most often teachers fail to "recognize and understand the emotional impact" faced by culturally or ethnically diverse students, resulting in non-retention of such students in educational institutions (Soto 2005, 860). The flip side of this discourse (sometimes requiring critical judgements and discussions) is the emotional impact on teachers who work in a global environment or specifically with diverse children in the 
USA. Care in this instance could be displayed as an evangelical action to emancipate, save, or help the 'marginalized other' rather than celebrating the differences by applying intercultural sensitivity. For example, Madrid, Baldwin and Belbase inform that many teachers especially from affluent Western countries undergo an emotional trauma when their "deeply held cultural ideologies" are disrupted (2016, 3). Their research with six American pre-service teachers in a cross-cultural context reveals some disturbing themes, such as the perpetuation of "the privileged Westerner and the Marginalized Other," and attitudes of agency based on the "cultural practices of the host country" $(2016,8)$. Their conclusive findings disclose the "frustration" of these American teachers with the "educational practices" in the host country and a "national love for their own Western ideologies" (2016, 8). They warn that ignoring such responses may lead newly trained teachers to problematically "reproduce dominant assumptions about the education of young children" in diverse contexts $(2016,3)$. Therefore, it is essential to deconstruct the pedagogy of 'care' for our pre-service teachers so that they recognize that caring in education is not about saving or emancipation, but rather about accepting differences and making an effort to cultivate intercultural communication through intercultural sensitivity.

\section{Infusing Diversity Across the Curriculum: Approaches in Developing ICC and a 'Caring Pedagogy'}

"Infusing diversity across the curriculum" is a yearlong project supported and funded by the Nakatani Teaching and Learning center at UW-Stout. During the year 2014-2015, I participated in this project to understand personally perceived and coconstructed conceptions of culture and diversity through a semester-long assignment with my Early Childhood Education (ECE) students. The primary aim of this project was to develop definitions of culture and diversity through a subjective inquiry into the personal lives of my students via reflective journal writings. I conducted this inquiry to understand how my group of predominantly white, female students from a mid-western, semi-rural university represented and perceived their culture and what understandings they had about world cultures and diversity. The ethical application was approved on the fifth of April 2015 under the Code of Federal Regulations Title 45 Part 46 by the UW-Stout Institutional Review Board (IRB). The IRB is a federally mandated review board that protects the "rights and welfare of human research subjects" (See http://www.uwstout.edu/rs/irb.cfm). Informal consent was obtained from all students as the project was designed as a class assignment. Students were randomly assigned numbers and instructed to write this number on their narrative submissions to maintain anonymity. If students wished to withdraw from the project, they were asked to submit the narratives with their names on them instead of the random number. There were no consequences for withdrawing from the project. 
The design for this research project was based on a qualitative model. Data was collected through descriptive and reflective narratives written by 38 students (mainly sophomores) of two different sections of an ECE class. The project was introduced at the beginning of the semester as a writing assignment using letters of the English alphabet. Each week students from both sections were instructed to choose words from an alphabetical list and write a short reflective paragraph relating the word to their personal experiences. Section 001 students were allowed to choose random words from a prescribed list while Section 002 were instructed to choose specific words related to values, beliefs and/or culture. The initial data analysis revealed that $90 \%$ of section 001 had chosen simpler words from the given list, i.e., words such as 'adventure' and 'athletics' for letter A and 'basketball' and 'burger' for letter B were predominant. The narratives from the section 002 students were related to their experiences in the American context and expressed their thoughts on topics, such as 'anti-bias,' 'competition,' 'divorce,' 'family,' 'heritage,' etc. The descriptive data (written narratives) from both the sections were compared, contrasted and eventually analyzed, utilizing a thematic coding model provided by Braun and Clarke (2006). Similar ideas were grouped to reflect perceptions regarding culture, values, and cultural and ethnic differences through the experiences they expressed in the writings. Class discussions were conducted to collect views regarding the assignment and to assess student learning with both the sections each week. More in-depth discussions were conducted with student of section 002 regarding their narratives. The initial ideas that emerged from the data were relative to positive/negative life experiences, such as: family heritage, religion and church, individuality, competition, contentment, entitlement, divorce, separation, race, color, gender, socioeconomy, etc. These emerging themes were further analyzed and grouped into distinct categories of: individuality, pride, power, privilege, faith and whiteness. The limitations of the data are apparent due to the constrained size of the respondents (38 in total) and the fact that most, if not all, came from middle-class, white families from mid-western, semi-rural settlements and were predominantly female (32 female). Bennett's developmental model of intercultural sensitivity suggests that most people who grow up in culturally homogeneous environments and have limited contact with people outside their own culture group are often in the "denial stage" (1993, 110). They are either "indifferent" or ignorant about other cultures and peoples (Paige et al. 2003, 469). Limitations in the interpretations are also obviously based on the biases that my positionality (that of a non-American-NepaliAsian instructor) imposed on the data. Although I needed to maintain a degree of "ongoing self-awareness during the research process" so as not to skew the data, there were times when I had to acknowledge my predisposition to natural and human characteristics (Pillow 2003, 178). A small group of scholars suggest that assessments of ICC are based on human characteristics and that there are few who know how to measure these (Bennett 1993; Paige et al. 2003). In line with this observation, the interpretations below do not measure levels of ICC, rather they are my thoughts on and perceptions of the student-written narratives influenced by my positionality and my personal values and beliefs. 


\subsection{Individuality and Competitiveness}

Several students articulated the influence of their social upbringing on their individuality and competitive nature. Most students were involved in competitive activities such as sports and believed that winning mattered as it was an expected norm. Rottenberg describes these characteristics as "performativity" and suggests that they are linked to race, gender, and class. She further adds that "class norms" in the USA for example, "urged subjects to live up to regulatory ideals linked to the middle class" $(2008,12)$.

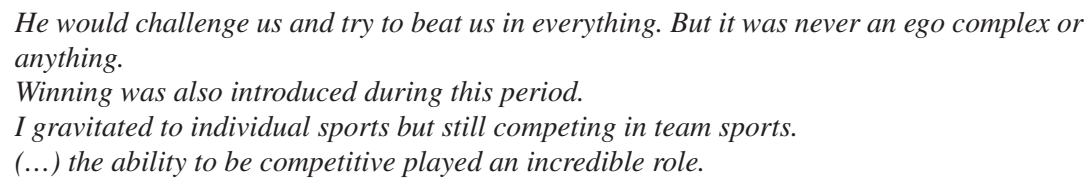

He would challenge us and try to beat us in everything. But it was never an ego complex or anything.

Winning was also introduced during this period.

I gravitated to individual sports but still competing in team sports.

(...) the ability to be competitive played an incredible role.

According to Rottenberg (2008), the class discourse disallows subjects to be initiated into society from the lower class and encourages climbing from one class to another. Therefore, performativity as the dominant norm influences the creation of one's identity through "repetitive effects on a subject through the discursive reiteration of its regulatory ideals" as the following excerpts illustrate.(Rottenberg 2008, 13).

Throughout high school, I had never believed in the word quit.

I think being so competitive and having victory [being] a huge part of me has to do with how I was raised.

There's always quotes hung up that say "Never give up" or "quitters never win."

Triandis describes individualism as an aspect of personality and states that individualist cultures perceive "the self as stable" while the context around the individual is fluid; therefore, individuals shape the environment to suit their personalities (2001, 920). Several respondents in this research were first-generation college attendees. Some of them came from rural areas and were from families who had lived in the same regions for many generations. These students stated that they were "taught from a young age to put [on]their town's glorious jersey and play hard." Wolfson suggests that American individualism has mutated over the last three decades and individualism has become more about competition and winning (1997, 77). Contrary to the trend of competitive individualism, most of the respondents belonged to families that romanticized the "conforming American of the 1950s," who, in search of "natural rights to life, liberty and the pursuit of happiness," joined and became part of a civil society to escape obscurity and poverty (Wolfson 1997, 79). For example, many students who participated in this research expressed that they "live in a great community" and some were very aware of what was expected of them, such as "successfully completing their studies and getting a good job" or "getting married and settling down." However, "winning" and "being ahead" were primary responses. 


\subsection{Heritage and Family: Pride and Power}

There was a strong sense of pride among the participants regarding their familial and ancestral heritage. For example, many of them mentioned being blessed to have acquired a particular first or last name as it was considered a valuable family legacy. This could be an expression of historically situated social policies that underpin the predominance of families as the "basic unit of society" although many scholars note the rapid changes occurring in American family units today (Kagan 2009, 4). For example, Angier writes that recent research reveals that families are "becoming more socially egalitarian" and are more "ethnically, racially, religiously and stylistically diverse" than before (2013). Despite the changes in family structures across the United States, this research noted that most of the respondents' families were homogeneous, with white parents of opposite sexes, and religiously affiliated to a Church, which was their prime source of community support. The male respondents were proud to uphold the family name, indicating the dominant masculine culture and elitist attitudes. The white female respondents outnumbered the handful of male participants, and, in a similar mindset, indicated that working with children is a woman's job and an expectation of the society. The data was devoid of discussions regarding ethnicity and/or race, signifying an intergenerational trend of white, middle-class conformity shaped by the experiences of their ancestors.

To this day, I thank my father for naming me after him because I know it's a piece of family heritage that he passed down to me.

At an early age, my Aunt instilled pride into my life. She used to repeat regularly remember you're a "___ " act like it!

I think pride is incredibly important because it's something local communities all the way up to our federal government need to instill in its citizens. If individuals weren't prideful we couldn't have advanced and progressed as much as we have.

\subsection{Privilege of Whiteness and Socio-economy: Opportunity and Entitlement}

Jean and Feagin suggest that "a family's memory is crucial to its identity and to its members' identity" (1998, 297). Cross and Madson describe this identity as the "self." They argue that the self is a "dynamic cultural creation" formed by "selfviews, and emotions" and impacted by the "cultural values, ideals, structures and practices" of a particular context $(1997,6)$. The participants of this research revealed several instances where their self-identity was based on values and ideals such as family, status, whiteness and socio-economy. These, they claimed, were responsible for their success as they were "blessed to have so many opportunities to develop" and were aware that "opportunity and advantages really are key predictors for success." Socio-economy played a crucial role in the formation of their self and some participants stated that "money means a lot more than that; it means a way of living, experiencing new things and also a way to go out and get away or go out and have 
fun." Being and belonging to white families and communities was an indicator of socio-economical emancipation and entitlement as some students noted that "socioeconomic status can have a lot to do with many types of things, usually being in your favor." This emancipatory assertion subtly specifying their white-privilege showed through in their affluence, as some of them owned "a cabin they would go to for weekend getaways" while others owned a "sailboat." While participants claimed to be aware of classism and their designated place in the societal class structure, the data and research outcome did not divulge much dialogue regarding race and ethnicity. For example, few participants mentioned the Black or AfricanAmerican experience and suggested that "all children are the same," indicating a "color-blindedness" (Apfelbaum et al. 2012). Apfelbaum et al. note that this kind of behavior is "routinely exhibited by teachers seeking to model equality in their classrooms" (2012, 206).

\subsection{Faith and Religion}

Volumes of research studies have confirmed that children in families and communities who regularly practice some form of religious practice have healthier and positive outcomes (Smith 2003). This was evident in this research as several respondents mentioned how "God and faith" were "very important" in their lives. Some stated that "God loved them" and "has a plan for their lives." These imply that the participants' behavior and actions are highly influenced by their beliefs, faith and religion. Several research studies also mention that individuals who are religiously affiliated are better able to cope with stressful events as their "religious and spiritual systems may be a valuable source to make meaning from their experiences" (Krok 2015, 202).

\subsection{Afterthoughts}

Through these excerpts, most students revealed that their culture consisted of things that they valued, loved or respected. However, it was evident that these individual intricacies were difficult for them to acknowledge as their individual "culture" or cultural identity. Most assumed that their cultural identity was based on a whole (white and American and at times white-American Wisconsinites) rather than in smaller parts (immigrant heritage, family belief systems, religion, upbringing, socio-economy, race, gender etc.). These narratives confirm that most students were never guided to investigate their cultural identities through a reflective or a subjective lens. Dedeoglu and Lamme emphasize that "views of reality" are social constructions given "personal meaning by their life experiences" (2011, 470). As mentioned above and suggested by Bennett and Bennett (2004), objective views of culture are institutional and can pertain to "political and economic systems" while subjective views relate to the "experiences of the social reality formed by the 
society's institution." They inform that both views subsist as a dichotomy. According to them, "objective culture is internalized through socialization" while "subjective culture is externalized through role behavior" $(2004,150)$. Through the narratives above, it can be assumed that internalized values (from their families and upbringing, education, and/or, religious communities) were being externalized through their actions (individualistic, competitive and prideful) and that this was probably the reason why all students insisted, that their predominant culture was that of "middle class, white and American," and that "hard work" to be "successful" was their primary value or belief. Several scholars confirm that teachers' beliefs and values impact their instructional approaches and how they view children from other cultures (Hachfeld et al. 2015; Gay 2010; Milner 2010). Therefore, it can be assumed that beliefs about one's own culture and upbringing influence how teachers view teaching and working with children from diverse backgrounds. Commonly held beliefs about the importance of individualism, competition, pride and entitlement among my pre-service teachers perpetuate hegemony and reject the notion of intercultural sensitivity. This in turn, eliminates the very essence of a caring pedagogy because one can only care or empathize with other people and other cultures if one becomes aware of their own culture and socio-cultural backgrounds. A pedagogy of care can only be indulged if one rejects the "white knight going to teach in innercity schools to save the poor minority children" attitude and entitlement and see "others" eye to eye and treat them like human beings just like themselves (Garmon 2005, 207).

\section{Conclusion: Visions and the Step Forward}

Developing ICC, as the literature claims, is not an easy overnight task. It requires participants to be introspectively mindful of not only their own culture but to be able to "deconstruct the discourse of mono-culturalism" (Rhedding-Jones 2007, 39). Teachers need to delve deeply into understanding their ethnocentric views regarding development, teaching and learning and replace them with ethno-relativity through a reflective process (Bennett and Bennett 2004). The development model of intercultural sensitivity (DMIS) by Bennett and Bennett (2004) relies on the theoretical premises of "personal construct" and "radical constructivism," both of which are intimately related to human emotions. Madrid et al. state that it is imperative for teachers to recognize these emotions and the "discomfort" that becomes apparent when their "deeply held cultural ideologies" are threatened while trying to develop intercultural sensitivity $(2016,3)$.

Therefore, the development of ICC is reliant on how teachers interpret these underlying tenets of the self; and, it is contingent on how teachers explore and interpret their own values, beliefs and prejudices (Campbell et al. 2012). ICC requires a critical examination of thoughts through reflective actions, problem-solving skills, an ability to recognize and deconstruct assumptions, and a resolution to constantly question personal dogmas. Instructors in teacher education must continuously chal- 
lenge the "deficit thinking" model by "engaging in a critique of society's sociopolitical structures" with pre-service teachers, and by encouraging them to discover the missing link that will bridge the widening gap that social constructs such as "race, gender roles, and culture" accentuates. However, these gaps can only be reconceptualized if we learn to care for and about others (Hartlep et al. 2015, 142) because without care and empathy - these visions will not be realized.

If you find it in your heart to care for somebody else, you will have succeeded. Maya Angelou

\section{References}

Angier, N. (2013). The changing American family. The New York Times.

Apfelbaum, E. P., Norton, M. I., \& Sommers, S. R. (2012). Racial color blindness: Emergence, practice, and implications. Current Directions in Psychological Science, 21(3), 205-209.

Barton, A. C. (2001). Capitalism, critical pedagogy, and urban science education: An interview with Peter McLaren. Journal of Research in Science Teaching, 38(8), 847-859.

Bennett, J. M. (1993). Cultural marginality: Identity issues in intercultural training. In R. M. Paige (Ed.), Education for the intercultural experience (pp. 109-135). Yarmouth: Intercultural Press.

Bennett, J. M., \& Bennett, M. J. (2004). An integrative approach to global and domestic diversity. In D. Landis, J. M. Bennett, \& M. J. Bennett (Eds.), Handbook of intercultural training (pp. 147-165). Thousand Oaks: Sage.

Braun, V., \& Clarke, V. (2006). Using thematic analysis in psychology. Qualitative Research in Psychology, 3(2), 77-101.

Britzman, D. P. (1991). Decentering discourses in teacher education: Or, the unleashing of unpopular things. The Journal of Education, 173(3), 60-80.

Campbell, M. R., Thompson, L. K., \& Barrett, J. R. (2012). Supporting and sustaining a personal orientation to music teaching: Implications for music teacher education. Journal of Music Teacher Education, 22(1), 75-90.

Cochran-Smith, M., Stern, R., Gabriel, J., Sánchez, A. M., Keefe, E. S., Fernández, M. B., Chang, W. C., Cummings, M., Carney, S. B. Baker, M., 2016. Holding teacher preparation accountable: A review of claims and evidence. Boulder: National Education Policy Center. [Online] http://nepc.colorado.edu/publication/teacher-prep. Accessed 10 Jan 2018.

Cross, S. E., \& Madson, L. (1997). Models of the self: Self-construals and gender. Psychological Bulletin, 122(1), 5 .

Dai, X., \& Chen, G. M. (2014). On interculturality and intercultural communication competence. China Media Research, 11(3), 100-114.

Darling-Hammond, L. (2006). Constructing 21st-century teacher education. Journal of Teacher Education, 57(3), 300-314.

Dean, T. (1989). Multicultural classrooms, monocultural teachers. College Composition and Communication, 40(1), 23-37.

Dedeoglu, H., \& Lamme, L. L. (2011). Selected demographics, attitudes, and beliefs about diversity of preservice teachers. Education and Urban Society, 43(4), 468-485.

Florian, L. (2017). Teacher education for the changing demographics of schooling: Inclusive education for each and every learner. Teacher Education for the Changing Demographics of Schooling: Issues for Research and Practice, 2, 9.

Fonseca-Greber, B. (2010). Social obstacles to intercultural competence in America's language classrooms. Center for Educational Resources in Culture, Language and Literacy (CERCLL) (NJ3). 
Garmon, M. A. (2004). Changing preservice teachers' attitudes/beliefs about diversity: What are the critical factors? Journal of Teacher Education, 55(3), 201-213.

Garmon, M. A. (2005). Six key factors for changing preservice teachers' attitudes/beliefs about diversity. Educational Studies, 38(3), 275-286.

Gay, G. (2010). Culturally responsive teaching: Theory, research, and practice. New York: Teachers College Press.

Hachfeld, A., Hahn, A., Schroeder, S., Anders, Y., \& Kunter, M. (2015). Should teachers be colorblind? How multicultural and egalitarian beliefs differentially relate to aspects of teachers' professional competence for teaching in diverse classrooms. Teaching and Teacher Education, $48,44-55$.

Hartlep, N. D., Porfilio, B. J., Otto, S., \& O'Brien, K. (2015). What we stand for, not against: Presenting our teacher education colleagues with the case for social foundations in PK-12 teacher preparation programs. The Journal of Educational Foundations, 28(1-4), 135.

Kagan, S. L. (2009). American early childhood education: Preventing or perpetuating inequity. In Equity matters: Research review (Vol. 3). New York: The Campaign for Educational Equity, Teachers College, Columbia University. [Online]. http://citeseerx.ist.psu.edu/viewdoc/downlo ad?doi=10.1.1.526.5604\&rep=rep1\&type=pdf. Accessed 10 Jan 2018.

Kayes, P. E. (2006). New paradigms for diversifying faculty and staff in higher education: Uncovering cultural biases in the search and hiring process. Multicultural Education, 14(2), 65.

Krok, D. (2015). The role of meaning in life within the relations of religious coping and psychological well-being. Journal of Religion and Health, 54(6), 2292-2308.

Ledwell, K., \& Oyler, C. (2016). Unstandardized responses to a "standardized" test: The edTPA as gatekeeper and curriculum change agent. Journal of Teacher Education, 67(2), 120-134.

Madrid, S., Baldwin, N., \& Belbase, S. (2016). Feeling culture: The emotional experience of six early childhood educators while teaching in a cross-cultural context. Global Studies of Childhood, 6(3), 336-351.

Maxwell, L. A. (2014). US school enrollment hits majority-minority milestone. The Education Digest, 80(4), 27.

Milner, H. R., IV. (2010). What does teacher education have to do with teaching? Implications for diversity studies. Journal of Teacher Education, 61(1-2), 118-131.

Paige, R. M., Jacobs-Cassuto, M., Yershova, Y. A., \& DeJaeghere, J. (2003). Assessing intercultural sensitivity: An empirical analysis of the hammer and Bennett intercultural development inventory. International Journal of Intercultural Relations, 27(4), 467-486.

Pillow, W. (2003). Confession, catharsis, or cure? Rethinking the uses of reflexivity as methodological power in qualitative research. International Journal of Qualitative Studies in Education, $16(2), 175-196$.

Rhedding-Jones, J. (2007). Monocultural constructs: A transnational reflects on early childhood institutions. TCI (Transnational Curriculum Inquiry), 4(2), 38-54.

Rissanen, I., Kuusisto, E., \& Kuusisto, A. (2016). Developing teachers' intercultural sensitivity: Case study on a pilot course in Finnish teacher education. Teaching and Teacher Education, $59,446-456$.

Rottenberg, C. (2008). Performing Americanness: Race, class, and gender in modern AfricanAmerican and Jewish-American literature. New England: UPNE.

Sahlberg, P. (2004). Teaching and globalization. Managing Global Transitions, 2(1), 65.

Smith, C. (2003). Religious participation and network closure among American adolescents. Journal for the Scientific Study of Religion, 42(2), 259-267.

Soto, N. E. (2005). Caring and relationships: Developing a pedagogy of caring. Vill L Rev, 50, 859.

St. Jean, Y., \& Feagin, J. R. (1998). The family costs of white racism: The case of African American families. Journal of Comparative Family Studies, 297-312.

Trainer, T. (2012) 'Education' under consumer-capitalism, and the simpler way alternative (Simplicity Institute Report 12m, 2015). [Online]. http://simplicityinstitute.org/wp-content/ uploads/2011/04/TrainerEducationSimplicityInstitute.pdf. Accessed 10 Jan 2018. 
Triandis, H. C. (2001). Individualism-collectivism and personality. Journal of Personality, 69(6), 907-924.

United Nations Educational, Scientific and Cultural Organization (UNESCO). (2013). Intercultural competences: Conceptual and operational framework. Paris: UNESCO.

Weaver, G. (1999). American cultural values. Kokusai Bunka Kenshu (Intercultural Training) (Special Edition, pp. 9-15). [Online]. http://trends.gmfus.org/doc/mmf/American\%20 Cultural\%20Values.pdf. Accessed 10 Jan 2018.

Weiner, L. (2007). A lethal threat to US teacher education. Journal of Teacher Education, 58(4), 274-286.

Wolfson, A. (1997). Individualism: New and old. The Public Interest, 126(Winter), 75-88.

Wursten, H., \& Jacobs, C. (2013). The impact of culture on education. Can we introduce best practices in education across countries. ITIM International, 1, 1-28.

Zeichner, K. (2006). Reflections of a university-based teacher educator on the future of collegeand university-based teacher education. Journal of Teacher Education, 57(3), 326-340.

Open Access This chapter is licensed under the terms of the Creative Commons Attribution 4.0 International License (http://creativecommons.org/licenses/by/4.0/), which permits use, sharing, adaptation, distribution and reproduction in any medium or format, as long as you give appropriate credit to the original author(s) and the source, provide a link to the Creative Commons licence and indicate if changes were made.

The images or other third party material in this chapter are included in the chapter's Creative Commons licence, unless indicated otherwise in a credit line to the material. If material is not included in the chapter's Creative Commons licence and your intended use is not permitted by statutory regulation or exceeds the permitted use, you will need to obtain permission directly from the copyright holder.

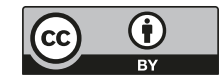

